\title{
The Contributions of Abyssal Hill Morphology and Noise to Altimetric Gravity Fabric
}

\author{
John A. Goff \\ University of Texas Institute for Geophysics - Austin, Texas USA \\ Walter H.F. Smith and Karen M. Marks \\ NOAA Laboratory for Satellite Altimetry • Silver Spring, Maryland USA
}

\section{Introduction}

Earth's deep seafloor is, for the most part, a vast, unexplored terrain. Only a miniscule fraction has ever been observed directly, using deep submersibles and remotely operated vehicles. Most of our understanding of seafloor physiography is instead derived from remotely sensed data, such as sonar or satellite altimetry. Sonar data must be collected by ships or underwater vehicles, which is an expensive and time-consuming process. Technological advances over the past two decades have enabled sonar devices to collect detailed "swath" coverage (Figures $1 b$ and $2 b$ ), but only a few percent of the seafloor has been mapped in this fashion, typically in areas of prominent seafloor structures such as mid ocean ridges, fracture zones and trenches. More generally, sonar coverage of the ocean floor is limited to profile coverage along disparate ship tracks, well concentrated in shipping lanes and very sparse elsewhere.

Over the past decade or so, satellite altimetry data have been employed to fill in the gaps left by incomplete sonar coverage. The marine geoid and the gravity field derived from it are dominated by the seafloor topography signal at scales less than a few hundreds of kilometers (Smith and Sandwell, 1997; Smith, 1998). Major seafloor features are easily detected in the altimetric gravity data (Figures $1 \mathrm{a}$ and $2 \mathrm{a}$ ), and their bathymetry can be predicted based on geophysical formulations constrained by existing bathymetric coverage. However, this predictive ability is severely limited at smaller scales. The altimetric gravity field is, in essence, a filtered and somewhat noisy expression of bathymetry (Smith, 1998). Depending on water depth, that filter is $\sim 18-20 \mathrm{~km}$ wide (full-wavelength); we cannot expect a one-to-one correspondence of gravity and seafloor features below this scale. Furthermore, noise would be translated in this predictive scheme into large bathymetric artifacts. Hence, little effort has gone into trying to interpret small-scale features in the gravity field.

However, as has been demonstrated previously (e.g., Smith, 1998; Goff and Smith, 2003) and will be shown here, geological information is contained in the small-scale fabric of altimetric gravity data. This fabric, which has the appearance of the skin of an orange peel, or the surface of a football, exists everywhere in the altimetry data, filling the otherwise uninteresting reaches between larger-scaled, recognizable features such as mid-ocean ridges, fracture zones and seamounts. Although noise is an important factor, small-scale gravity fabric, and rms roughness in particular, varies regionally in ways that are suggestive of a tectonic origin; that is, related to mid-ocean ridge spreading rates or ridge-axis morphology at the time of seafloor creation. Such variations must, in some way, be related to the small-scale (i.e., $<\sim 20 \mathrm{~km}$ full-wavelength) morphology of the seafloor.

In this study we examine the gravity roughness characteristics in two regions, the South Atlantic Ocean (Figure 1) and southeast Pacific Ocean (Figure 2), where changes in spreading rate over time have been observed in the magnetic anomaly record. We employ a statistical characterization method developed by Goff and Smith (2003) that provides estimates of root-means-square (rms) roughness, characteristic length and width, and strike azimuth to identify fabric. Our samples avoid major physiographic features, such as fracture zones, so that our expectation is that the measured gravity fabric is related to the primary fabric of the seafloor: abyssal hills, which constitute the most widespread geomorphology on Earth. Abyssal hills are related to the nature of the mid-ocean ridges at which they form (Goff, 1991; Goff, 1992; Goff et al., 1995; Goff et al., 1997). The seafloor roughness represented by abyssal hills is also of interest to the physical oceanographic community because of the critical role it plays in ocean circulation and mixing (e.g., Mauritzen et al., 2002).

Through synthetic experiments we demonstrate theoretically the relationship between gravity fabric and abyssal hills at a variety of sizes and shapes. We explore as well the effect of noise on our ability 

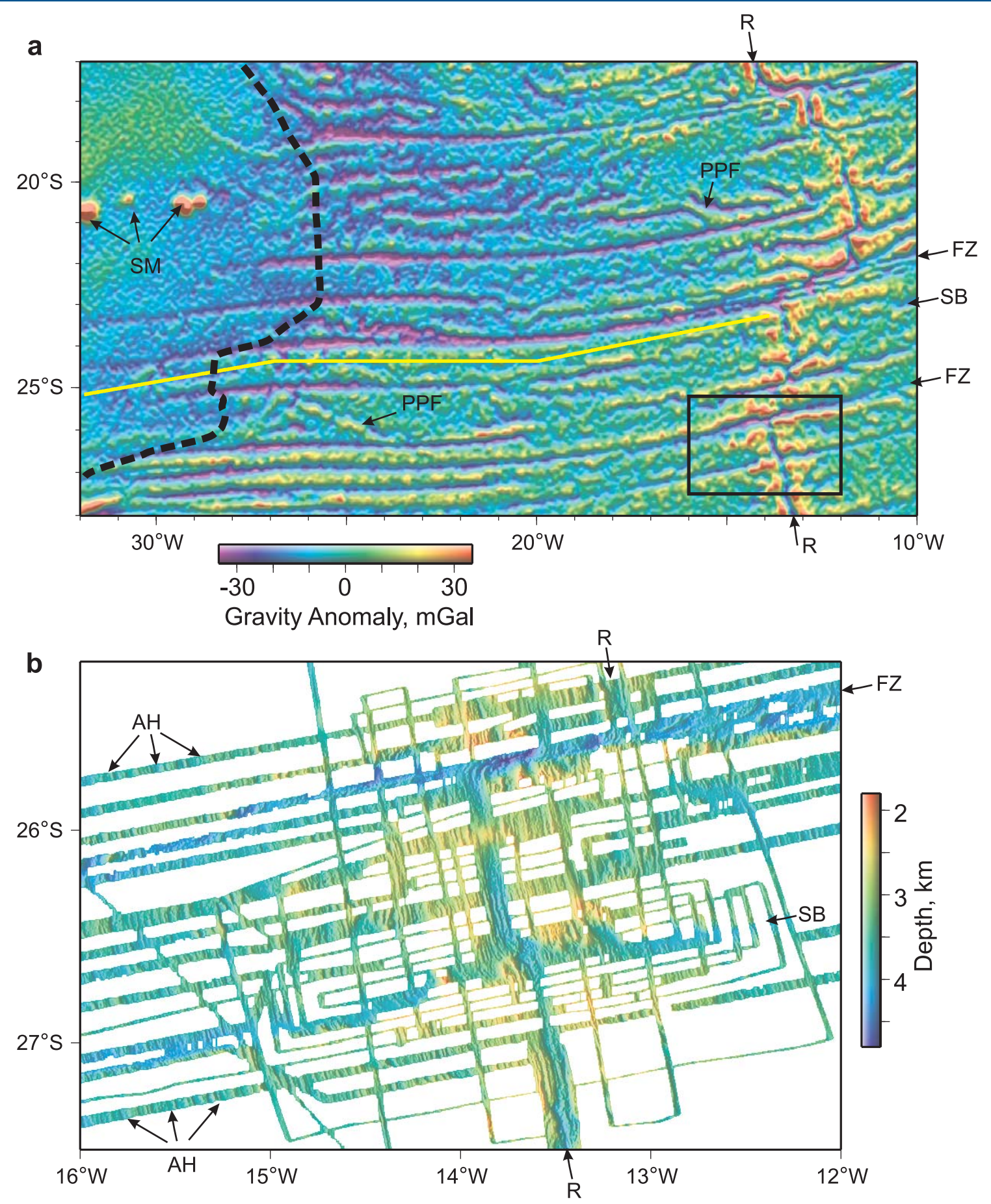

Figure 1. Satellite altimeters can map marine gravity anomalies associated with seafloor structure. Altimeter data collected to date (top image, $\boldsymbol{a}$ ) display the main features of classical plate tectonics (mid-ocean ridges, " $R$," and fracture zones, "FZ"), seamounts ("SM"), and some finer-scale features associated with transient or unstable aspects of the seafloor spreading process (propagator pseudofaults, "PPF," and axial segment boundaries, "SB"). At still smaller scales, the altimetric gravity image displays a bumpy texture like the surface of an orange peel. Though this texture seems random, it does change from place to place, often along sharp boundaries (heavy dashed line). In this paper we show that this bumpy texture can in fact be correlated with very small-scale seafloor topographic features known as abyssal hills, which are traditionally visible only in multibeam acoustic swath bathymetry (bottom image, $\boldsymbol{b}$; hills at "AH"). The area shown here is in the South Atlantic Ocean; the bathymetry image at bottom zooms in on the boxed region shown in the top image. Note the gaps in bathymetric coverage; this area is extremely well covered by global bathymetric standards. A profile along the heavy yellow line is shown in Figure 4. (Altimetric gravity from Sandwell and Smith, 1997. Bathymetry from the Ridge Multi-Beam Synthesis Project http://ocean-ridge.ldeo.columbia.edu). 
to resolve abyssal hill-related gravity fabric, and investigate the possible improvements that may be achieved by a new altimetry mission that significantly reduces the level of noise in the data set.

\section{Seafloor Morphology and Fabric Estimation}

The morphology of the deep seafloor is composed of a variety of features that exist at a range of scales (Figures 1 and 2). Apart from seamounts, which are typically isolated structures formed off axis, most of these features are derived from the mid-ocean ridges, where new oceanic crust is formed as tectonic plates spread apart. Fracture zones are the largest and most prominent of such structures. Created by the transform faults that link ridge offsets, fracture zones form ribbon-like trench and ridge structures oriented orthogonal to the ridge axis at the time of crustal accretion. Fracture zones are commonly observed in satellite altimetry data (Figures 1a and 2a). Akin to fracture zones are segment boundaries, small non-transform offsets in the ridge axis that produce disturbances in the crust and, if large enough, evidence in the altimetry data (Figure 1a). Segment boundaries that are not stable can migrate up and down the ridge axis, creating diagonal lineaments called "propagator psuedofaults" (Figures $1 \mathrm{a}$ and $2 \mathrm{a})$.

Between the fracture zones and segment boundaries, the seafloor is composed primarily of abyssal hill fabric: ridge-parallel lineaments created by a combination of volcanic construction and tectonic extension at or near the mid-ocean ridge axis (e.g., Macdonald and Atwater, 1978; Kappel and Ryan, 1986; Macdonald et al., 1996; Figures $1 b$ and 2b)(Box 1). Abyssal hills are responsive to the ridge environment. For example, abyssal hills heights and widths tend to correlate inversely with spreading rates (Goff, 1991; 1992; Malinverno, 1991; Bird and Pockalny, 1994; Macario et al., 1994; Goff et al., 1997), and increase in size when a mid-ocean ridge changes from an axial high to an axial valley (Goff et al., 1997). Abyssal hills also change morphology depending on crustal thickness and magma supply (Goff et al., 1995), factors which can vary within a single ridge segment and/or can vary from one ridge segment to another. Abyssal hills are therefore an off-axis indicator of mid-ocean ridge spreading history.

To extract the information contained in the abyssal hill record, we must quantify abyssal hill morphology. Quantification can be done either deterministically (each feature examined individually) or statistically (features are examined as ensemble averages). The choice depends largely on scale and numbers. Large features that are few in number, such as fracture zones and mid-ocean ridges, are best quantified deterministically. Small features that are numerous, such as abyssal hills, are best quantified statistically; here, the individual feature contains insufficient information, because the same mid-ocean ridge process can produce a range of sizes and shapes.

Goff and Jordan (1988) developed a method for quantitative characterization of abyssal hill morphology based on swath bathymetric coverage. The method employs a least-squares inversion of the sample twodimensional covariance function to estimate parameters of a functional form: the "von Kármán" model (von Kármán, 1948), which is a band-limited fractal. The following statistical parameters are derived from this model:

The rms height, $H_{b}$, measures the overall bathymetric roughness.

The characteristic scale, $\lambda_{b}$, measures the horizontal scale of the most prominent feature size, and is defined as twice the second moment of the covariance function (Goff and Jordan, $1988) ; \lambda_{b n}$, the characteristic width, is measured normal to the strike direction, and $\lambda_{b s}$, the characteristic length, is measured along the strike direction. The ratio between characteristic length and width, $a_{b}=\lambda_{b s} / \lambda_{b n}$, provides a measure of fabric.

The strike azimuth, $\theta_{b}$, measures the orientation of abyssal hill lineaments.

The fractal dimension, $D$, measures the level of fine-scale roughness compared to large-scale roughness. In practice, this parameter is difficult to estimate because swath bathymetry does not provide a largeenough range of scales between the resolution scale $(\sim 200 \mathrm{~m})$ and the characteristic scale $(\sim 2-5 \mathrm{~km})$. Typically, this value is assumed to be $\sim 2.2-2.3$, consistent with multi-scale analysis of abyssal hills (Goff and Tucholke, 1997).

Were the entire seafloor mapped with multibeam data, we could employ this parameterization to explore the history of mid-ocean ridge spreading throughout most of Earth's ocean basins. However, as noted elsewhere in this issue, swath mapping is a slow and expensive process; it has been estimated (Carron et al., 2001) that a systematic survey of the seafloor would require $\sim 200$ years of ship time at a costs of billions of U.S. dollars. Very little of the seafloor has been mapped with swath sonar methods, and only a small fraction will be mapped in such detail for the foreseeable future. We therefore seek to extract as much information about seafloor morphology as we can from satellite altimetry data. However, because of the intrinsic filtering associated with gravitational response of the sea surface to seafloor topography (Smith, 1998; Smith and Sandwell, this issue), individual abyssal hills will typically not be distinguishable in the altimetry data. Nevertheless, gravity data, like the seafloor, exhibits a small-scale fabric; one that can be quantified with statistical methods and which may, without attempting a 

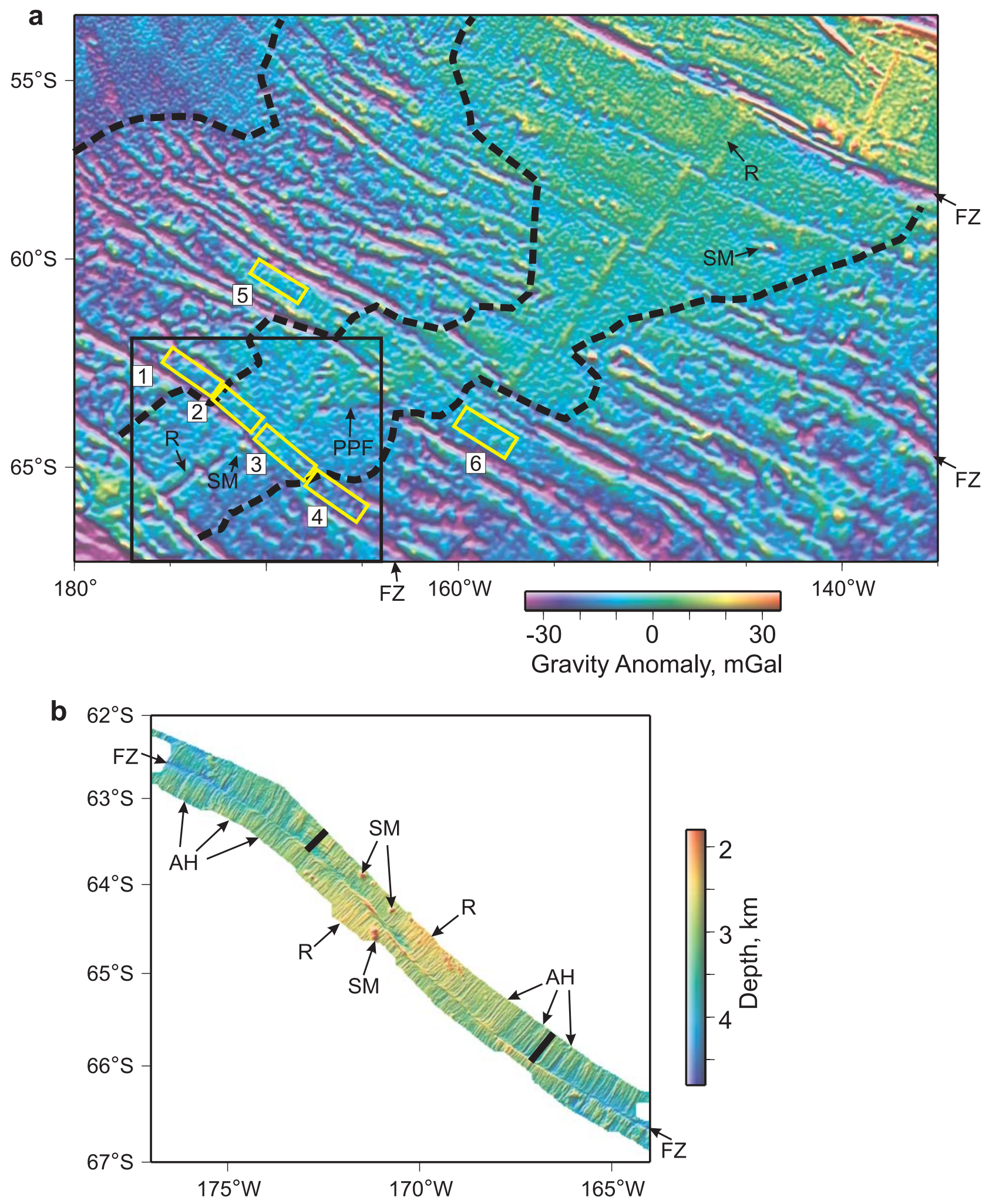

Figure 2. Satellite altimeter gravity image ( $(a)$ and zoom to available swath bathymetry (b), as in Figure 1, though now showing the southwestern Pacific instead of the South Atlantic. The altimetric gravity shows changes in background texture (a, heavy dashed black lines) apparently associated with changes in the number and spacing of fracture zones. Numbered yellow boxes indicate regions selected for texture analyses given in Table 1. The solid black box area is zoomed in the bottom image showing swath bathymetry. Gravity from Sandwell and Smith, 1997; bathymetry from Cande et al., 1995. 


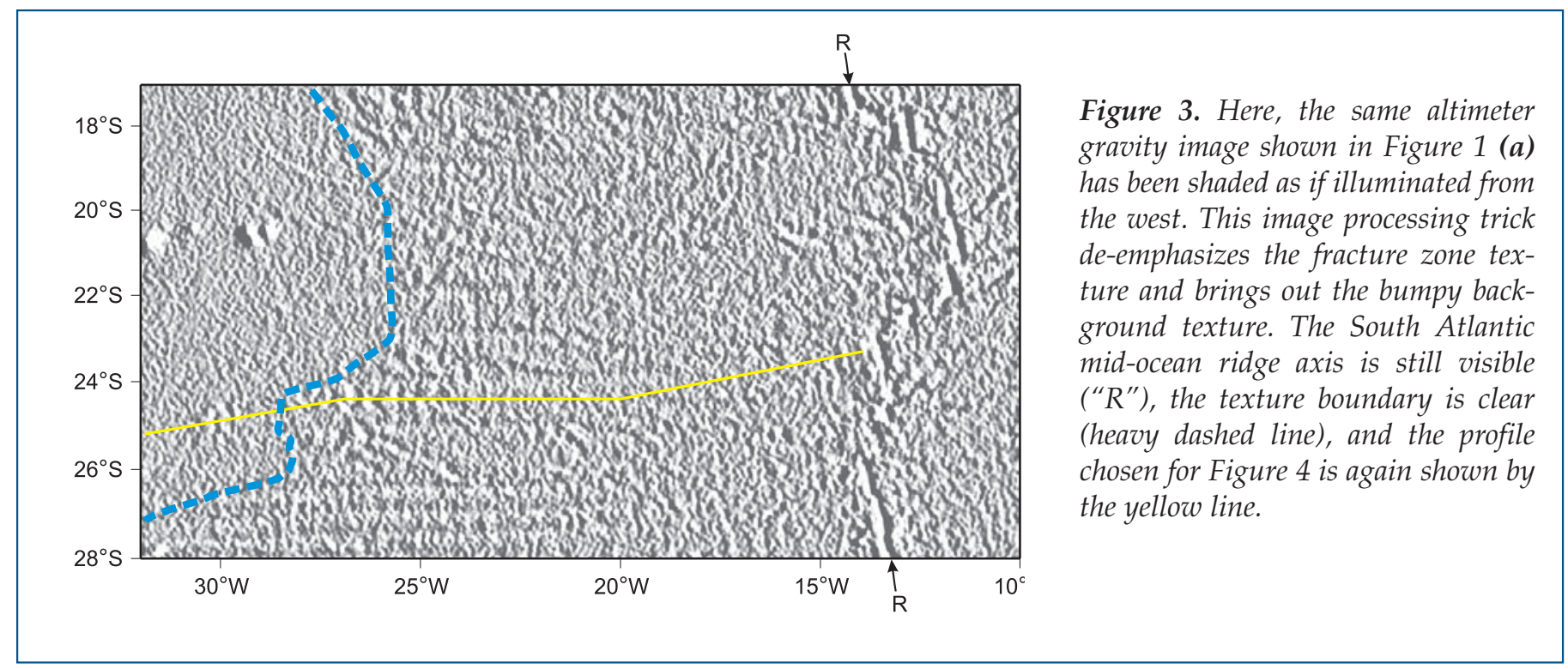

one-to-one feature match, correspond in some way to the abyssal hill fabric on the seafloor (Smith, 1998; Goff and Smith, 2003). To characterize gravity fabric, Goff and Smith (2003) adapted the Goff and Jordan (1988) methodology for abyssal hill characterization, substituting a Gaussian form in place of the von Kármán model because the processed gravity data are smooth, i.e., non-fractal. The inverted parameters of the Gaussian covariance model provide equivalent measurements to the bathymetric parameters above: $H_{g}, \lambda_{g n}$ $\lambda_{g s}\left(\right.$ or $\left.a_{\mathrm{g}}=\lambda_{g s} / \lambda_{g n}\right)$ and $\theta_{g}$.

\section{Gravity Fabric}

We examine two examples of regional gravity roughness variations that appear well-correlated to changes in spreading rate over time and to known variations in abyssal hill morphology.

\section{South Atlantic}

The north-illuminated gravity map of the South Atlantic Ocean displayed in Figure 1a is dominated by fracture zone and segment boundary features. High fracture zone densities are typical of slow spreading rates such as the southern Mid-Atlantic Ridge (MAR), which has spread at a full rate of $<\sim 50 \mathrm{~mm} / \mathrm{yr}$ for the past $75 \mathrm{Ma}$ (Cande et al., 1988). The disappearance of many of these fracture zones in the westernmost region of Figure 1a corresponds to an abrupt change in spreading rate $(>75 \mathrm{~mm} / \mathrm{yr})$ at this isochron. A different view of this same gravity data set is seen when illuminated from the east (Figure 3). Here the fracture zones are barely discernible; we observe instead a gravity fabric that exhibits a general increase in roughness westward away from the spreading axis, and then an abrupt drop at essentially the same location as the change in fracture zone density noted in Figure 1a.

The above qualitative observations are most easily quantified by estimating the rms gravity roughness. Of the statistical parameters, rms roughness is the simplest to measure, is the least prone to uncertainties, and most closely compares with qualitative observations. Figure 4a displays a detrended profile along a flow line identified in Figures 1a and 3. This profile was chosen because it lies between two stable fracture zones that are far enough apart that we can be confident that the fracture zones themselves are not influencing the profile. The rms gravity roughness derived from this profile (Figure $4 \mathrm{~b}$ ) gradually increases westward away from the axis, and then abruptly decreases (here at longitude $28^{\circ} \mathrm{W}$ ), consistent with the qualitative observations above. Comparison with the spreading rates over this same corridor (Cande et al., 1988) demonstrates that the gravity rms is closely correlated (negatively) with spreading rate through most of the profile (Figure $4 \mathrm{~b})$. This relationship does not continue east of $20^{\circ} \mathrm{W}$; here rms gravity decreases eastward toward the axis even as spreading rate decreases. However, as noted by in a number of studies (e.g., Kong et al., 1988; Goff et al., 1995; Tucholke et al., 1997; Bonatti et al., 2003), crustal accretion at slow spreading ridges and the resulting off-axis morphology can be highly variable, subject to changes that are related as much to temporal and spatial variability in magma supply as to spreading rate. In this flow line in particular, we note that the southern of the two bounding fracture zones loses its clear definition east of $\sim 17.5^{\circ} \mathrm{W}$ (Figures $1 \mathrm{a}$ and 3 ). This may be an indication of changes in the crustal accretion process within this ridge segment.

Such variability is also in evidence in a study of abyssal hills along four flow lines in the South Atlantic region (Goff, 1992). Although the individual flow lines exhibit considerable variability in abyssal hill relief, when the results are averaged by crustal age they display a clear negative correspondence with spreading rate. An abrupt change in abyssal hill relief at $\sim 75 \mathrm{Ma}$ 


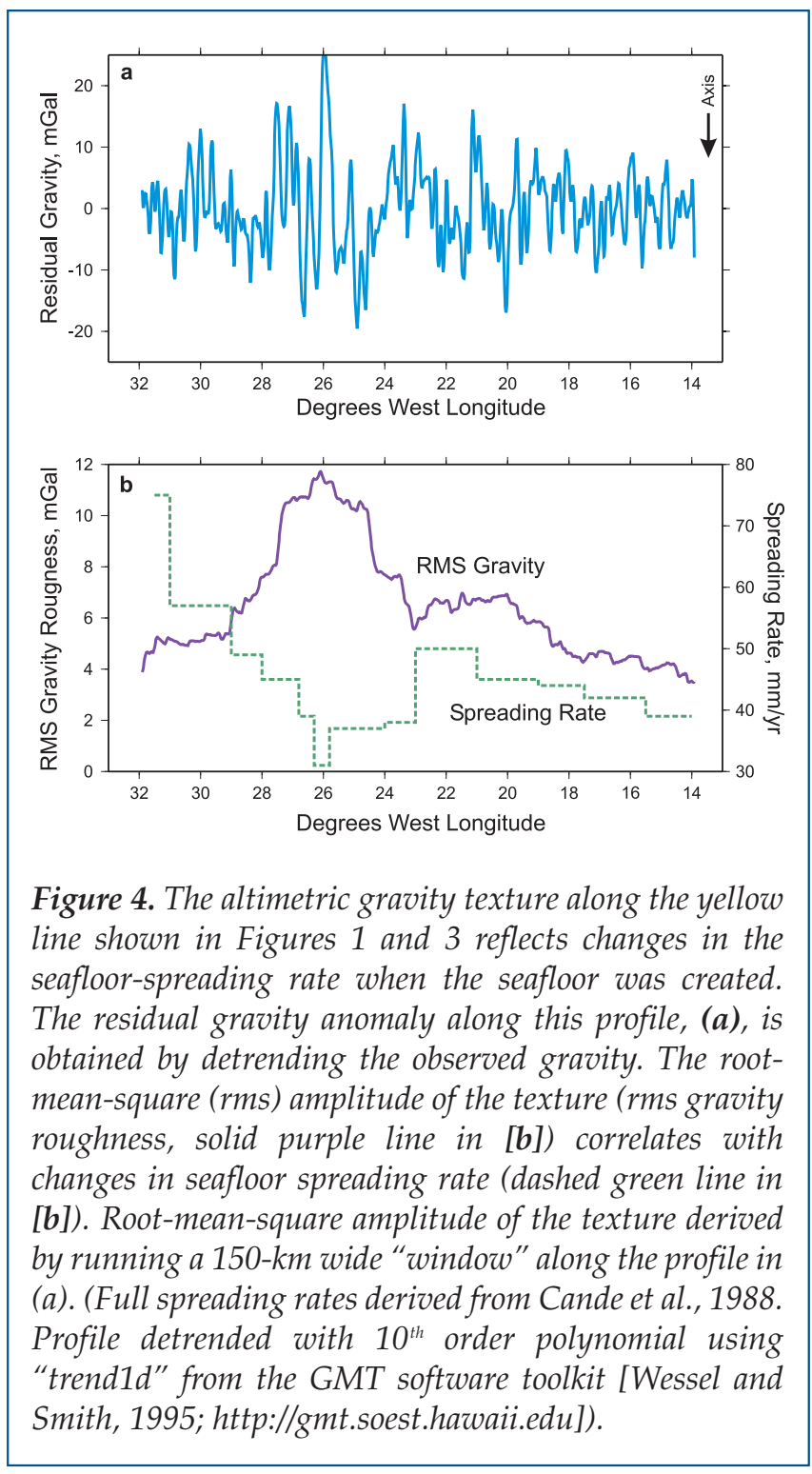

can be seen in both flow lines that cross that isochron.

The above example demonstrates two important points: (1) away from fracture zones or other "deterministic" features of the altimetric gravity field, gravity roughness displays regional changes that likely correspond at least in part to tectonic changes, and (2) abyssal hills on average exhibit some of the same trends, so that we can reasonably assume a possible link between the two.

\section{Southeast Pacific}

Like the southern MAR, the Pacific-Antarctic Ridge (PAR) in the Southeast Pacific Ocean (Figure 2) has undergone changes in off-axis morphology associated at least in part with changes is spreading rate (Macario et al., 1994; Géli et al. 1997). Changes in fracture zone intensity (Figure 2a) again correspond to changes in gravity roughness as seen when illuminated parallel to the fracture zones (Figure 5). Abyssal hills mapped along the Pitman Fracture Zone (Figure $2 b$ ) were analyzed by Macario et al. (1994) using the Goff and Jordan (1988) methodology. They found an abrupt decrease in abyssal hill rms and characteristic width with decreasing crustal age at $\sim 6-8 \mathrm{Ma}$ that corresponded to a increase in spreading rate from $\sim 40 \mathrm{~mm} / \mathrm{yr}$ to nearly $60 \mathrm{~mm} / \mathrm{yr}$ at that time (Figure 2b).

To investigate gravity fabric in this example, we follow the method of Goff and Smith (2003) by selecting subsample boxes that avoid major fracture zones (Figures 2a and 5), and estimate gravity fabric parameters $H_{g}, \lambda_{g n}, \lambda_{g s}\left(\right.$ or $\left.a_{g}=\lambda_{g s} / \lambda_{g n}\right)$ and $\theta_{g}$. Four boxes (1-4) were chosen adjacent to the Pitman Fracture Zone, and partially contain the area of bathymetric data analyzed by Macario et al. (1994). The boundaries between boxes 1 and 2 and between boxes 3 and 4 are at the locations where Macario et al. (1994) discerned a change in abyssal hill morphology. These locations correspond as

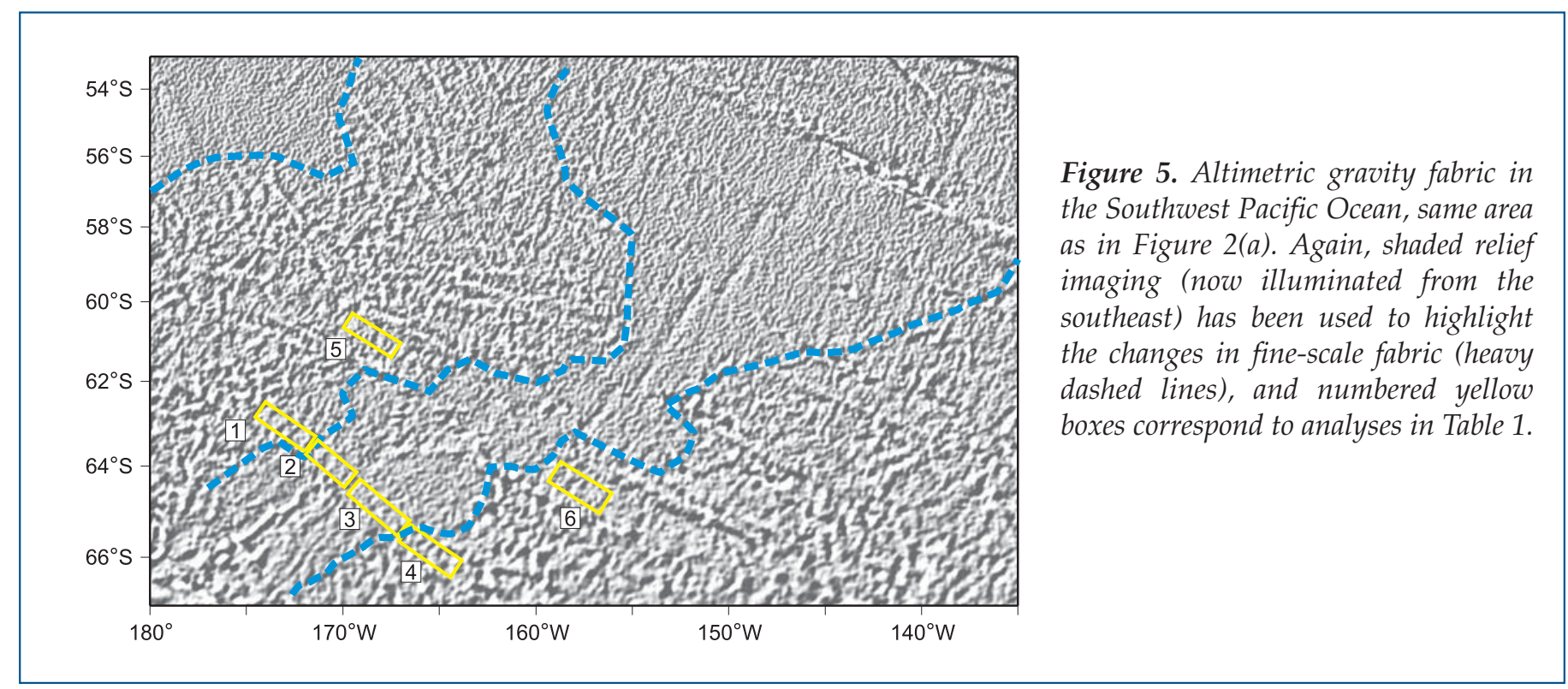




\section{Table 1}

Statistical parameters estimated from sample gravity boxes identified in Figures $2 a$ and 5 .

\begin{tabular}{c|c|c|c|c|c} 
Box & $H_{g,} \mathrm{mGal}$ & $\lambda_{g^{\prime}}, \mathrm{km}$ & $\lambda_{g s^{\prime}} \mathrm{km}$ & $a_{g}$ & $\Theta_{g^{\prime}}$ degrees \\
\hline 1 & $4.91 \pm 0.49$ & $13.1 \pm 1.6$ & $17.2 \pm 4.3$ & $1.31 \pm 0.31$ & $41 \pm 19$ \\
\hline 2 & $3.30 \pm 0.28$ & $11.2 \pm 1.5$ & $12.7 \pm 2.3$ & $1.13 \pm 0.20$ & $2 \pm 50$ \\
\hline 3 & $3.02 \pm 0.22$ & $11.0 \pm 2.0$ & $11.7 \pm 1.4$ & $1.06 \pm 0.19$ & $-21 \pm 33$ \\
\hline 4 & $4.88 \pm 0.44$ & $12.7 \pm 1.7$ & $14.2 \pm 2.7$ & $1.11 \pm 0.21$ & $8 \pm 54$ \\
\hline 5 & $4.08 \pm 0.45$ & $12.2 \pm 1.8$ & $21.3 \pm 5.2$ & $1.75 \pm 0.41$ & $21 \pm 10$ \\
\hline 6 & $3.77 \pm 0.36$ & $12.8 \pm 1.8$ & $17.7 \pm 3.7$ & $1.38 \pm 0.28$ & $36 \pm 16$ \\
\hline
\end{tabular}

$H_{g}:$ rms height; $\lambda_{g n}$ : characteristic width; $\lambda_{g s}$ : characteristic length; $a_{g}$ : aspect ratio $\left(\lambda_{g s} / \lambda_{g n}\right) ; \Theta_{g}:$ strike azimuth.

Table 2

Mean abyssal hill properties for identified regions (Goff et al., 1997) with expected contribution to rms gravity roughness assuming $3000 \mathrm{~m}$ and $4000 \mathrm{~m}$ upward continuation (UC) and a density contrast of $1800 \mathrm{~kg} / \mathrm{m}^{3}$ at the seafloor. Process filtering and residual noise are not factored in.

\begin{tabular}{|c|c|c|c|c|c|c|}
\hline \multirow[b]{2}{*}{ Region } & \multirow[b]{2}{*}{$\begin{array}{l}\text { Spreading Rate, } \\
\mathrm{mm} / \mathrm{yr}\end{array}$} & \multicolumn{3}{|c|}{ Abyssal Hill Characteristics } & \multicolumn{2}{|c|}{ RMS Gravity Roughness, mGa } \\
\hline & & $\bar{H}_{b}, \mathrm{~m}$ & $\bar{\lambda}_{b n}, \mathrm{~km}$ & $\overline{a_{b}}$ & $3000 \mathrm{~m}$ UC & $4000 \mathrm{~m}$ UC \\
\hline Pacific-Nazca ${ }^{a}$ & 160 & 58.7 & 2.90 & 5.11 & 1.31 & 1.07 \\
\hline Pacific-Cocos ${ }^{b}$ & 110 & 56.1 & 2.00 & 6.62 & 0.96 & 0.78 \\
\hline SEIR Axial High ${ }^{c}$ & 75 & 61.7 & 1.76 & 6.29 & 0.97 & 0.78 \\
\hline SEIR Intermediate $^{c}$ & 75 & 97.4 & 3.10 & 6.30 & 2.22 & 1.85 \\
\hline SEIR Axial Valleyc & 75 & 169.8 & 3.95 & 6.00 & 4.43 & 3.73 \\
\hline PAR fast ${ }^{d}$ & 55 & 90 & 4.0 & $6.0^{*}$ & 2.36 & 2.00 \\
\hline PAR slow ${ }^{d}$ & 40 & 140 & 6.0 & $4.0^{*}$ & 4.32 & 3.68 \\
\hline Southern MARa & 40 & 200.9 & 5.65 & 2.98 & 5.71 & 4.79 \\
\hline Southern MARe & 35 & 222 & 5.96 & 2.59 & 6.32 & 5.29 \\
\hline Northern MAR ${ }^{f}$ & 28 & 235.8 & 8.21 & 3.26 & 8.20 & 7.07 \\
\hline
\end{tabular}

$\bar{H}_{b}$ mean rms height; $\bar{\lambda}_{b n}$ mean characteristic width; $\bar{a}_{b}$ mean aspect ratio.

aGoff et al. (1993); b ${ }^{\mathrm{G}}$ off (1991); ${ }^{\circ} \mathrm{Goff}$ et al. (1997); ${ }^{\mathrm{C}}$ Macario et al. (1994); e Neumann and Forsyth (1995);

fGoff et al. (1995).

*Assumed value. 

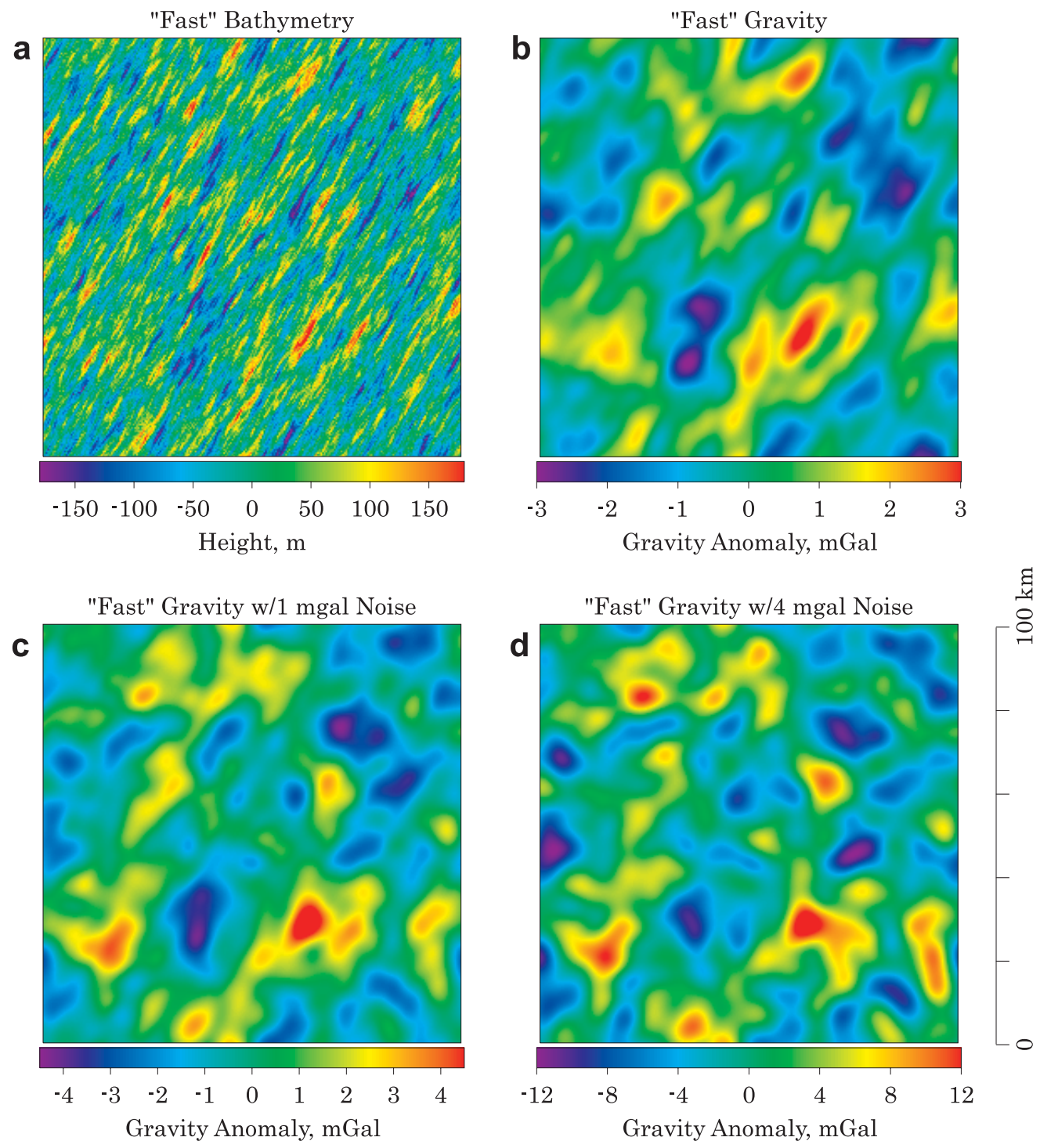

Figure 6. This model uses the average statistical properties of the Pacific-Cocos region (Table 2) to represent "fast" seafloor fabric. Note that the north-northeast orientation of the underlying hills can be detected in the noise-free (b) and $1 \mathrm{mGal}$ noise models (c), but is obscured if the noise level reaches $4 \mathrm{mGal}(\boldsymbol{d})$.

General Key to Figures 6, 7, and 8. These are synthetic models to show how the finest scale of seafloor fabric (abyssal hills) would appear in satellite altimeter maps of the marine gravity field, under various assumptions about additional "noise" in the altimetric gravity. In Figure 6 (labeled "fast") the hill size is scaled to represent typical hill sizes created at a fast-spreading mid-ocean ridge; in Figure 7 ("intermediate") and Figure 8 ("slow") the hill sizes are scaled to represent typical seafloor of intermediate- and slow-spreading origin. In each figure, the top left image (a) is the abyssal hill signal in bathymetry, the top right (b) is the corresponding sea surface gravity signal, the lower left (c) assumes a 1 milliGal ( $m G a l)$ noise level, which a future mission could obtain, and the lower right (d) assumes a $4 \mathrm{mGal} \mathrm{noise} \mathrm{level,} \mathrm{which} \mathrm{approximates} \mathrm{the} \mathrm{situation} \mathrm{with}$ existing data. Note the change in amplitude of the color scales in Figures 6, 7, and 8. In all of these models, the same seafloor density contrast $\left(1800 \mathrm{~kg} / \mathrm{m}^{3}\right)$ and mean water depth $(3 \mathrm{~km})$ are assumed. All models use the same statistical realization of random phase, and the same north-northeast orientation of the long axis of the hills, to facilitate comparison. 
well to where we have visually identified a change in gravity fabric (Figure 5).

The results of the parameter inversion from these boxes are presented in Table 1 with 1-standard deviation $(\sigma)$ uncertainties. The two boxes on older crust ( 1 and 4) have resolvably higher rms than the two boxes on younger crust (boxes 2 and 3 ), and marginally resolved higher characteristic scales. Of these four boxes, only box 1 exhibits what may be a resolved fabric and strike $\sim$ parallel to the abyssal hill trend. Two other examples on older crust along a nearby flow-line (boxes 5 and 6 in Figures 2a and 5) exhibit more wellresolved (within standard errors) fabrics and abyssal hill-parallel strikes (Table 1).

We observe, therefore, with estimation of gravity fabric parameters a likely correspondence of horizontal scales as well as rms roughness with spreading rate and abyssal hill morphology changes. We also find some, although not uniform, evidence for a fabric orientation in the gravity data that corresponds, within errors, to the expected strike of abyssal hills.

\section{Synthetic Upward Continuation}

Having established a probable empirical link between abyssal hill morphology and altimetric gravity fabric, we seek to establish this connection theoretically. This can be done using the "upward continuation" formulation (Smith, 1998), which specifies the gravitational field at the sea surface as a linear filter of the topography at the seafloor. The filter is dependent on two parameters: the density contrast at the seafloor (here assumed to be $1800 \mathrm{~kg} / \mathrm{m}^{3}$ ) and the mean water depth.

Upward continuation of bathymetry can be performed either on real data examples (Smith, 1998) or synthetics (realizations of the statistical model for abyssal hill morphology; Goff and Jordan, 1988). Both have distinct advantages and disadvantages. For real data, a direct comparison can be made between prediction and data, but we are limited by swath bathymetric data coverage and by complicating, non-abyssal hill elements that typically exist in any survey map. Synthetic data, although purely hypothetical, allow us to isolate the abyssal hill morphology from other factors, and to examine multiple independent realizations of the same statistical morphology.

Synthetic abyssal hill morphology can be generated by a fast Fourier method (Goff and Jordan, 1988). From the power spectral model (the Fourier transform of the covariance function model), the amplitude spectrum is derived by taking the square root. After multiplying the amplitude spectrum by a random phase spectrum, fast Fourier transformation yields the synthetic topography. The upward continuation gravity prediction is derived by multiplying the amplitude spectrum by the spectral filter function prior to multiplication by the random phase spectrum.

A table of average abyssal hill statistical properties organized by region and spreading rate (Goff et al.,
1997) provides the basis for our first examination of the expected contribution of abyssal hill morphology to gravity fabric (Table 2). We add to this list the averaged abyssal hill values from the Macario et al. (1994) study for slower and faster spreading regions along the PAR. Here we focus on the first-order observation of rms gravity roughness, and compute the expected value at $3000 \mathrm{~m}$ (i.e., near the mid-ocean ridge axis) and $4000 \mathrm{~m}$ (well away from the axis) upward continuation depths. We stress at this point that noise is not factored into these values. It is likely, for example, that the $\sim 1 \mathrm{mGal}$ rms contribution predicted for the Southeast Indian Ridge (SEIR) Axial High region and at faster spreading rates will not be detectable in the presence of a noise that is probably in the range of 2-4 mGal, depending on region. However, the rms values predicted for SEIR intermediate, axial valley and slower spreading rates are significant in relation with the range of rms values exhibited in Figure 4 and Table 1. It is therefore probable, based on this simple theoretical examination, that variations in abyssal hill morphology are contributing significantly to observed variations in gravity fabric.

\section{Noise}

Noise is an important contributor to gravity fabric at small scales, and it must be accounted for theoretically in order to ascertain as well the contribution from abyssal hills. The altimetric gravity field is a differentiation of the geoid field, which is what altimetry actually measures. An uncorrelated, or white, noise in the geoid field will result in a "blue" (increasing power at decreasing wavelength) gravity noise field. Filtering is essential to produce a stable data field (Sandwell and Smith, 1997). The gravity data employed in this study were filtered at a full wavelength of $14.6 \mathrm{~km}$, which is expected to produce a characteristic scale of roughly half that value. Examining altimetric gravity data over the axial high portions of the SEIR, where we expect little contribution from abyssal hills (Table 2), Goff and Smith (2003) obtained a gravity rms of $\sim 4 \mathrm{mGal}$ and an isotropic characteristic scale of $\sim 9 \mathrm{~km}$; they concluded that these values are primarily a result of the contribution of noise to the processed altimetric gravity data set in this region. The $4 \mathrm{mGal} \mathrm{rms} \mathrm{value} \mathrm{is} \mathrm{likely} \mathrm{to} \mathrm{be} \mathrm{large}$ compared to other oceanic regions because the SEIR has some of the highest average sea states anywhere (e.g., Young, 1999). For example, with estimated rms values as low as $3 \mathrm{mGal}$, the contribution of noise in the PAR region (Figures 2 and 5; Table 1) must be less. Assuming that the contributions of noise and signalrelated gravity are additive (i.e., total variance $=$ noise variance + signal variance, where variance $=\mathrm{rms}^{2}$ ), the rms values in Table 1 are, given the expected abyssal hill-related rms values listed in Table 2, theoretically consistent with an rms noise in the range of $\sim 2-3 \mathrm{mGal}$.

To systematically explore the effects of gravity noise on the resolution of abyssal hill-related gravity fabric, we perform parameter estimations on synthetic predicted gravity fields with a noise field added. We 

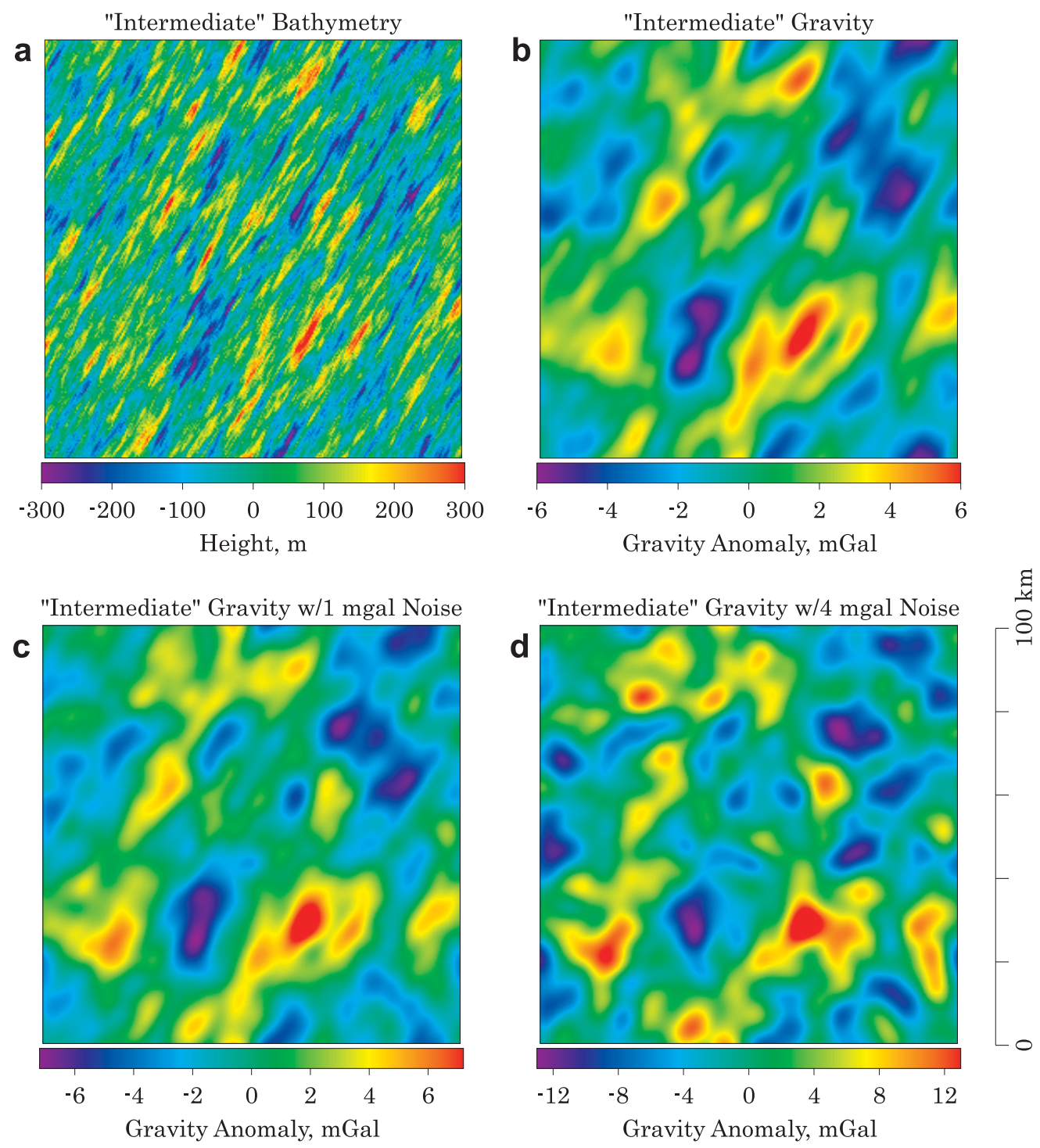

Figure 7. This model uses the average statistical parameters of the South-East Indian Ridge region ("SEIR-Intermediate" in Table 2) to represent "intermediate" seafloor fabric. Note that the hill orientation may be just barely resolved at the $4 \mathrm{mGal}$ noise level, $(d)$.

assume an additive noise characterized by an isotropic Gaussian covariance function with characteristic scale $\lambda_{N}=8.5 \mathrm{~km}$. The effects of noise are investigated by adding noise at a range of rms values $H_{N}: 1,2,3$, and 4 $\mathrm{mGal}$. An rms of $4 \mathrm{mGal}$ was found by Goff and Smith (2003), whereas $1 \mathrm{mGal}$ represents the target noise level for a future altimetry mission (Smith and Sandwell, this issue). We limit our experiment to three typical models: "slow," "intermediate," and "fast," which correspond closely to the average parameters of the Southern MAR (40 mm/yr), SEIR Intermediate, and Pacific-Cocos regions, respectively, listed in Table 2. An arbitrary strike orientation of $30^{\circ}$ was assumed for each.

Figures 6-8 each display a synthetic bathymetric realization, an upward continuation gravity prediction $(3000 \mathrm{~m})$, and the gravity plus noise at 1 and $4 \mathrm{mGal}$ for the three models. The same random phase spectrum was used for each to facilitate comparison. Without noise, the three upward continuation predictions (Figures $6 \mathrm{~b}, 7 \mathrm{~b}$ and $8 \mathrm{~b}$ ) look similar: differences in horizontal gravity scaling are subtle, despite the changes in the abyssal hill scales between the three models. Importantly, the $30^{\circ}$ strike orientation is discernable in each of the gravity predictions. The principal difference between these plots is evident in the vertical scale bars, which range \pm 3 times the rms. With the addition of noise, the three gravity predictions begin to change character. At $1 \mathrm{mGal}$ noise, the $30^{\circ}$ strike fabric is 

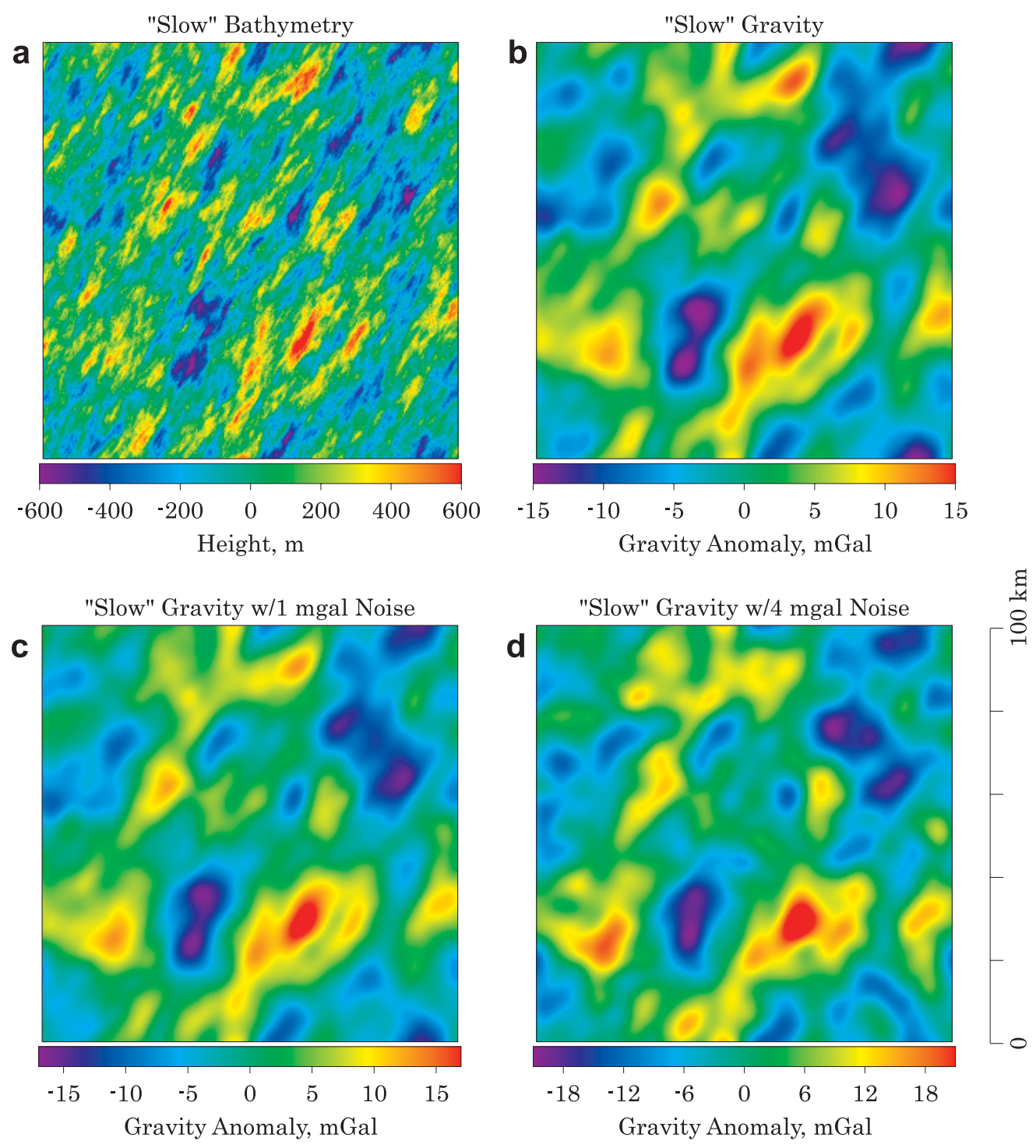

Figure 8. This model uses the average statistical parameters of the southern Mid-Atlantic Ridge ("Southern-MAR" in Table 2, $40 \mathrm{~mm} / \mathrm{yr}$ spreading rate) to represent "slow" sea floor. Note that the orientation of the hills is clear even in the presence of $4 \mathrm{mGal}$ noise $(d)$.

difficult to see in the "fast" model (Figure 6c), but is still evident in the "intermediate" (Figure 7c) and "slow" models (Figure 8c). At $4 \mathrm{mGal}$ noise, the abyssal hillrelated fabric is gone from both the "fast" (Figure 6d) and "intermediate" (Figure 7d) models, but is still evident in the "slow" model (Figure 8d).

Figure 9 displays parameter estimation results from the predicted gravity fields with the various noise contributions, which are plotted in relation to the "null" hypothesis that the results cannot be distinguished from noise. These results demonstrate quantitatively what was noted qualitatively in Figures 6-8: (1) gravity fabric associated with "slow"-type abyssal hills is resolvable at present-day noise levels; (2) gravity fabric associated with "intermediate" abyssal hills is marginally to poorly resolved at present-day noise levels, but is likely to be fairly well-resolved at noise levels anticipated for future missions with sufficient data sizes; and (3) gravity fabric associated with "fast" abyssal hills is not resolved at present noise levels, but may be partially resolved at future noise levels, again with sufficient data sizes.

\section{Challenges for the Future}

The evidence presented here quantitatively links the small-scale fabric of gravity data derived from satellite altimetry with the fabric of the ocean floor, abyssal hills. It is important to stress that this relationship is not 


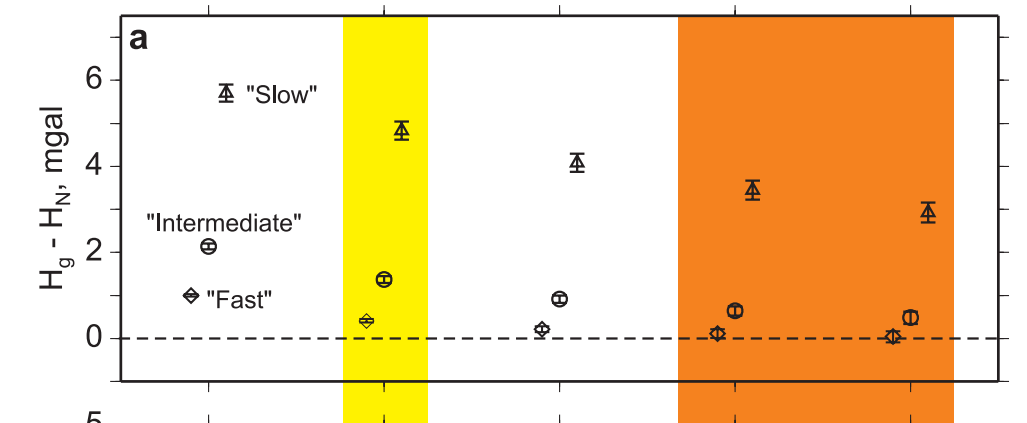

Figure 9. This diagram summarizes the results of our modeling, showing how well statistical parameters describing seafloor abyssal hill texture can be determined from satellite altimetry, even in the presence of measurement noise. The main conclusion is that the amplitudes and orientations of only the largest ("slow") hills are clearly resolved in existing data, due to its 3 to $4 \mathrm{mGal}$ noise level; however, a new mission achieving a $1 \mathrm{mGal}$ noise level would be able to resolve all important parameters of hills at all scales from all spreading types. Parameter estimation results for the upward-continued gravity models for the "slow," "intermediate." and "fast" abyssal hill statistical models, with added Gaussiancovariance noise of rms $H_{N}=1,2,3$ and 4 $m G$ al as indicated at bottom and characteristic scale $\lambda_{N}$ of $8.5 \mathrm{~km}$. Symbols are offset slightly with respect to $H_{N}$ to enhance visibility. The rms gravity, $H_{g}(a)$, and characteristic width, $\lambda_{g}(b)$, are plotted as differences with corresponding noise parameters to emphasize our ability to resolve abyssal hill-derived fabric by rejecting the null hypothesis, represented by horizontal dashed lines, that measured gravity fabric is simply noise. For the aspect ratio, $a_{g}$ (c) the null hypothesis is represented by the isotropic value of 1 . Vertical bars in $(\boldsymbol{a}),(\boldsymbol{b})$ and $(c)$ represent 1-standard deviation $(\sigma)$ error estimates, which are dependent on sample size and characteristic scales. As with aspect ratio, the estimated errors on strike azimuth $(d)$ provides a measure of our ability to resolve fabric in the presence of noise.

expressed as a one-to-one match between individual features in each field, but rather as a correspondence of statistical properties, parameterized by the rms variation, characteristic horizontal scales and strike orientation. It appears that the orientation of the long direction ("strike") of abyssal hills can be resolved by present data where the hills are among the largest typically found, and could be resolvable for hills of all sizes with a future mission having a lower noise level. While it may not be possible to invert gravity data directly for bathymetric roughness spectral parameters, it should be possible to provide indirect estimates based on established relationships between the two fabrics in the pres- ence of noise, particularly for the larger abyssal hills.

The quantitative connection between abyssal hill and gravity fabrics opens up the possibility of utilizing altimetry data to investigate seafloor fabric worldwide, which would be a benefit both for tectonic studies and for understanding oceanic mixing and circulation. However, significant challenges still face us. In particular, we must strive to understand, mitigate and reduce altimetric gravity noise. We must, for example, be able to predict the statistical properties of noise as a function of geographic location so that the contribution of seafloor morphology to the total gravity fabric can be ascertained. Even so, vast areas of the ocean floor 


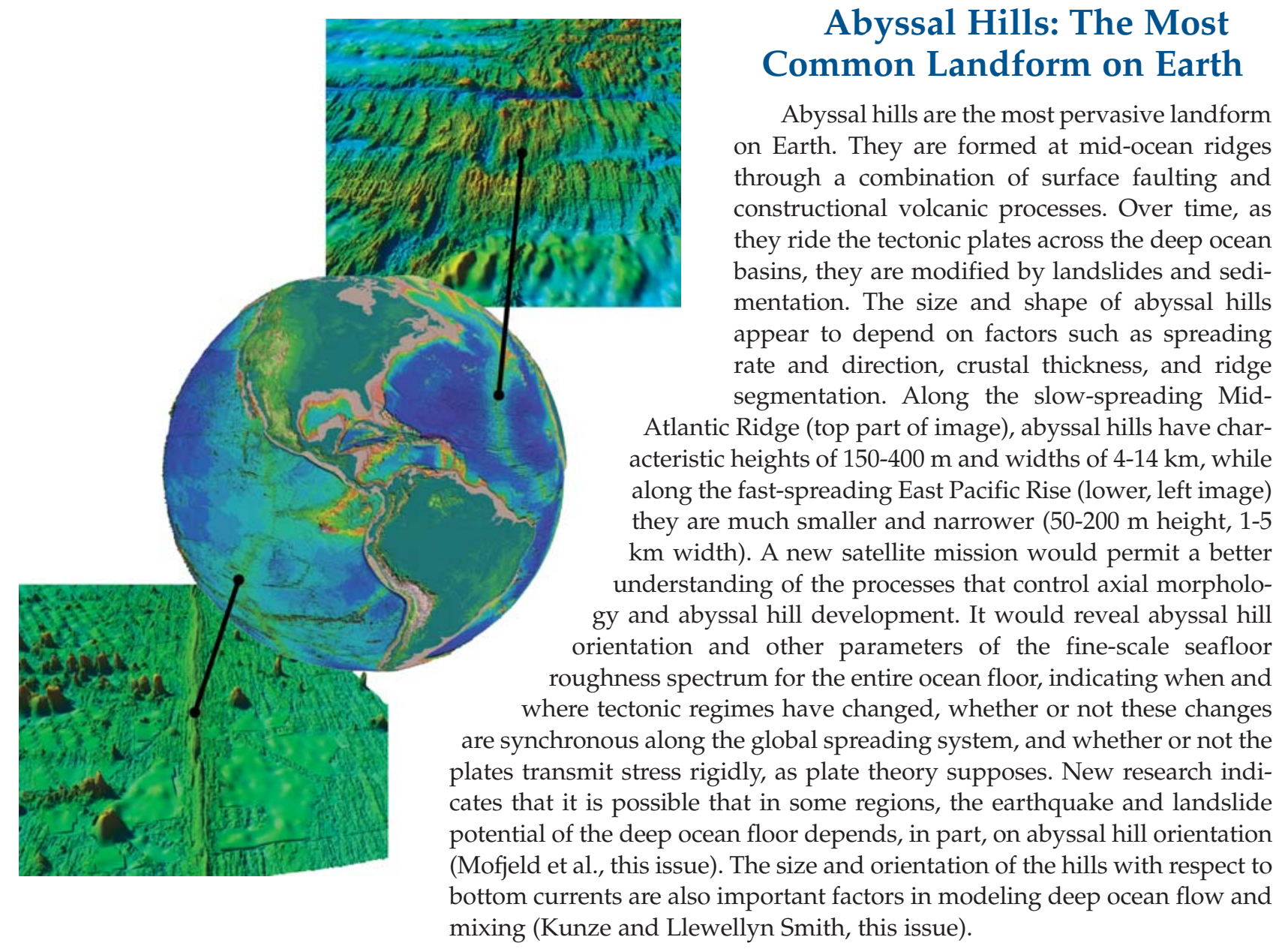

generated at faster spreading rates will not produce detectable seafloor fabric under present-day noise conditions. Only a significant reduction in noise level, as has been proposed for a new altimeter mission, will provide the opportunity to extract meaningful fabric estimates from these areas. 자

\section{Acknowledgements}

The authors acknowledge helpful input from David Sandwell. Graphics were generated using the Generic Mapping Tools (GMT) software package (Wessel and Smith, 1995). This is UTIG contribution \#1681. The views, opinions, and findings contained in this report are those of the authors and should not be construed as an official National Oceanic and Atmospheric Administration or U.S. Government position, policy, or decision.

\section{References}

Bird, R.T., and R.A. Pockalny, 1994: Late Cretaceous and Cenozoic seafloor and oceanic basement roughness: Spreading rate, crustal age and sedi- ment thickness corrections. Earth Plan. Sci. Lett., 123, 239-254.

Bonatti, E., M. Ligi, D. Brunelli, A. Cipriani, P. Fabretti, V. Ferrante, L. Gasperini, and L. Ottolini, 2003: Mantle thermal pulses below the Mid-Atlantic Ridge and temporal variations in the formation of oceanic lithosphere. Nature, 423, 499-505.

Cande, S.C., J.L. LaBrecque, and W.F. Haxby, 1998: Plate kinematics of the south Atlantic: Chron C34 to present. J. Geophys. Res., 93, 13,479-13,492.

Cande, S.C., C.A. Raymond, J. Stock, and W.F. Haxby, 1995: Geophysics of the Pitman fracture zone and the Pacific-Antarctic plate motions during the Cenozoic. Science, 270, 947-953.

Carron, M.J., P.R. Vogt, and W.-Y. Jung, 2001: A proposed international long-term project to systematically map the world's ocean floors from beach to trench: GOMaP (Global Ocean Mapping Program). Internat'l. Hydrogr. Rev., 2 (3, New Ser.), 49-55.

Géli, L., H. Bougault, D. Aslanian, A. Briais, L. Dosso, J. Etoubleau, J.-P. Le Formal, M. Maia, H. Ondréas, J.- 
L. Olivet, C. Richardson, K. Sayanagi, N. Seama, A. Shah, I. Vlastelic, and M. Yamamoto, 1997: Evolution of the Pacific-Antarctic ridge south of the Udintsev fracture zone. Science, 278, 1281-1284.

Goff, J. A., 1991: A global and regional stochastic analysis of near-ridge abyssal hill morphology. J. Geophys. Res., 96, 21,713-21,737.

Goff, J.A., 1992: Quantitative characterization of abyssal hill morphology along flow lines in the Atlantic Ocean. J. Geophys. Res., 97, 9183-9202.

Goff, J.A., and T.H. Jordan, 1988: Stochastic Modeling of Seafloor Morphology: Inversion of Sea Beam data for second-order statistics. J. Geophys. Res., 93, $13,589-13,608$.

Goff, J.A., and W.H.F. Smith, 2003: A Correspondence of Altimetric Gravity Texture to Abyssal Hill Morphology along the Flanks of the Southeast Indian Ridge. Geophys. Res. Lett., 30, doi:10.1029/ 2003/GL018913.

Goff, J.A., and B.E. Tucholke, 1997: Multi-scale spectral analysis of bathymetry on the flank of the MidAtlantic Ridge: Modification of the seafloor by mass wasting and sedimentation. J. Geophys. Res., $102,15,447-15,462$.

Goff, J.A., B.E. Tucholke, J.Lin, G E. Jaroslow, and M.C. Kleinrock, 1995: Quantitative analysis of abyssal hills in the Atlantic Ocean: A correlation between inferred crustal thickness and extensional faulting. J. Geophys. Res., 100, 22,509-22,522.

Goff, J.A., Y. Ma, A. Shah, J.R. Cochran, and J.-C. Sempéré, 1997: Stochastic analysis of seafloor morphology on the flank of the Southeast Indian Ridge: The influence of ridge morphology on the formation of abyssal hills. J. Geophys. Res., 102, 15,52115,534 .

Kappel, E.S., and W.B.F. Ryan, 1986: Volcanic episodicity and non-steady state rift valley along the northeast Pacific spreading centers: Evidence from Sea MARC I. J. Geophys. Res., 91, 13,925-13,940.

Kong, L.S., R.S. Detrick, P.J. Fox, L.A. Mayer, and W.B.F. Ryan, 1988: The morphology and tectonics of the Mark area from Sea Beam and Sea MARC I observations (Mid-Atlantic Ridge 23 N). Mar. Geophys. Res., 10, 59-90.

Macario, A., W.F. Haxby, J.A. Goff, W.B.F. Ryan, S.C. Cande, and C.A. Raymond, 1994: Flow line variations in abyssal hill morphology for the PacificAntarctic Ridge at 65S. J. Geophys. Res., 99, 17,92117,934 .

Macdonald, K.C., and T.M. Atwater, 1978: The evolution of rifted oceanic ridges. Earth Plan. Sci. Lett., 39, 319-327.

Macdonald, K.C., P.J. Fox, R.T. Alexander, R. Pockalny, and P. Gente, 1996: Volcanic growth faults and the origin of Pacific abyssal hills. Nature, 380, 125-129. of mid-ocean-ridge flank roughness on spreading rate. Nature, 352, 58-60.

Mauritzen, C., K.L. Polzin, M.S. McCartney, R.C. Millard, and D.E. West-Mack, 2002: Evidence in hydrography and density fine structure for enhanced vertical mixing over the Mid-Atlantic Ridge in the western Atlantic. J. Geophys. Res., 107, 3147, doi:10.1029/2001JC001114.

Neumann, G.A., and D.W. Forsyth, 1995: High resolution statistical estimation of seafloor morphology: Oblique and orthogonal fabric on the flanks of the Mid-Atlantic Ridge, $34^{\circ}-35.5^{\circ}$ S. Mar. Geophys. Res., $17,221-250$.

Sandwell, D.T., and W.H.F. Smith, 1997: Marine gravity anomaly from Geosat and ERS-1 satellite altimetry. J. Geophys. Res., 89, 1089-1104.

Smith, W.H.F., 1998: Seafloor tectonic fabric from satellite altimetry. Annu. Rev. Earth. Planet. Sci., 26, 697738.

Smith, W.H.F., and D.T. Sandwell, 1997: Global seafloor topography from satellite altimetry and ship depth soundings. Science, 277, 1956-1962.

Tucholke, B., J. Lin, M. Kleinrock, M. Tivey, T. Reed, J. Goff, and G. Jaroslow, 1997: Segmentation and crustal structure of the western Mid-Atlantic Ridge flank, $25^{\circ} 25^{\prime}-27^{\circ} 10^{\prime} \mathrm{N}$ and 0-29 m.y. J. Geophys. Res., 102, 10,203-10,223.

von Kármán, T., 1948: Progress in the statistical theory of turbulence. J. Mar. Res., 7, 252-264.

Wessel, P., and W.H.F. Smith, 1995: New version of the Generic Mapping Tools released. EOS Trans. Amer. Geophys. U., 76, 329.

Young, I.R., 1999: Seasonal variability of the global ocean wind and wave climate. Int. J. Climatol., 9, 931-950.

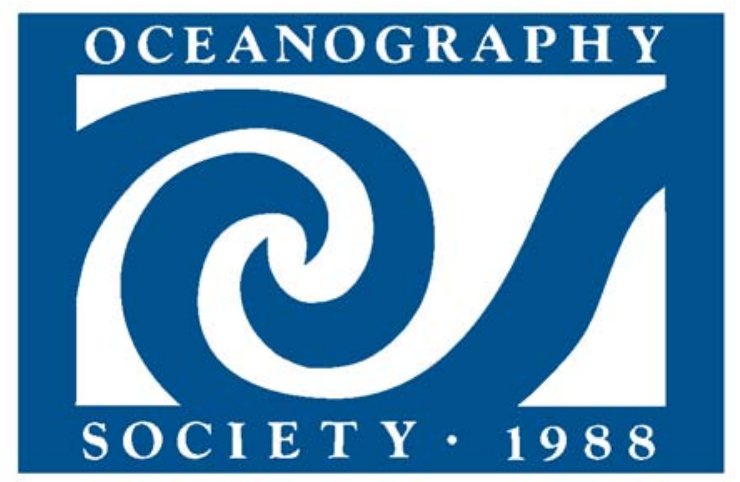

